\title{
TTR
}

Traduction, terminologie, re?daction

\section{Shanta Ramakrishna ed. Translation and Multilingualism: Post-Colonial Contexts. Delhi, Pencraft International, 1997.}

\section{Anke Rohde}

Volume 10, numéro 1, 1er semestre 1997

Langues, traduction et post-colonialisme

Languages, Translation and Post-Colonialism

URI : https://id.erudit.org/iderudit/037290ar

DOI : https://doi.org/10.7202/037290ar

Aller au sommaire du numéro

\section{Éditeur(s)}

Association canadienne de traductologie

ISSN

0835-8443 (imprimé)

1708-2188 (numérique)

Découvrir la revue

Citer ce compte rendu

Rohde, A. (1997). Compte rendu de [Shanta Ramakrishna ed. Translation and Multilingualism: Post-Colonial Contexts. Delhi, Pencraft International, 1997.]

TTR, 10(1), 303-309. https://doi.org/10.7202/037290ar d'utilisation que vous pouvez consulter en ligne.

https://apropos.erudit.org/fr/usagers/politique-dutilisation/ 
Shanta Ramakrishna ed. Translation and Multilingualism : Post-Colonial Contexts. Delhi, Pencraft International, 1997.

Translation and Multilingualism is a transnational collaboration by academics, translators and linguists in Canada and India. It is one of a number of publications on the theme of culture, language and translation, including Antoine Berman's L'épreuve de l'étranger, Sherry 
Simon's Le Trafic des langues, and Between Languages and Cultures, edited by Carol Maier and Anuradha Dingwaney, which have been steadily increasing in the past decade. Translation in this publication is defined as an activity which both reflects and affects intercultural relations. According to Shanta Ramakrishna :

There is an interplay of cross-cultural pride and prejudice, when one world is represented for another in translation. The translation of experiential categories, from one culture to another, be it regional, national or international, presents interesting theoretical issues. (p. 21)

With the underlying definition of translation as an intercultural activity, this collection of essays explores a number of themes such as multilingualism, language policy and planning, translation perspectives, and translation approaches and strategies.

Unlike translators in monolingual nations, Canadian and Indian translators share the experience of translating in a multilingual nation, as well as an awareness that translation is not only an intemational but also an intranational issue. It is therefore not surprising that Canadian and Indian specialists should want to compare translational policies and practices. Whereas translation has always been an integral part of the Canadian cultural and political history, India, despite the growing awareness of the importance of translation, has no well-defined policy. As a nation with 1,652 mother tongues and 18 official languages, translational issues in India are more complex than in Canada, where the attention has been focused on translation between the two official languages, French and English. Paul St-Pierre points out that the number of official languages in India alone "gives rise to 342 possible language combinations"(p. 136). The attempts of the Indian government to establish linguistic hegemony after independence and to replace English with Hindi as a national language proved unsuccessful. English was to be phased out after an adjustment period of 15 years, but regional conflicts over the institution of Hindi as a national language along with the strength of English as a global language of communication has kept English in place. The government eventually implemented a trilingual policy, which recognises Hindi (to further national unity), English (for administrative purposes) and regional languages (to maintain group identities). Both English and Hindi serve as link-languages connecting regional languages 
in the various states. The essays contained in this collection reflect some of the concerns and issues which preoccupy translators and linguists alike.

The essays contained in a section entitled MULTILINGUALISM describe and compare current linguistic practices in Canada and India. In "Multilingualism, Colonialism and Translation", R.K. Agnihotri not only provides the reader with invaluable information about the history of multilingualism in India, but also criticises the essentially monolingual approach to pedagogy in India. The author highlights the potential of the multilingual classroom. "A Troubled Turf", by Lakshmi Kannan reveals how uneven power differentials in India affect individuals. Kannan describes her experience of subverting both patriarchal and colonial power by acquiring an academic background in English. She proposes bilingualism, that is, combining the acquisition of regional languages with the acquisition of a global language, as a means of overcoming linguistic and cultural inequality. "Science Education, Language Dominance and Multilingualism" by Hansraj Dua reveals that despite all policy objectives, commissions, and recommendations, Indian languages do not seem to be in the position to realise the major goal of educational planning. Since English has become the dominant language not only in science education, but also in other domains, he recommends an increased commitment to the multilingual approach, to challenge the domination of English and to provide positive support for a multiplicity of perspectives and political justice. In a similar vein, "New Economic Policy and the Fate of Minority Languages" by Imtaz Hasnain maintains that the impact of the NEP on minority languages, especially its programme regarding the globalisation of the media through scheduled languages, will further marginalise minority linguistic groups. The essays that follow discuss the role of translation in a multilingual society. For Indra Nath Choudhouri, translation is an important tool in the negotiation of social tensions and language conflicts. In "Plurality of Languages and Literature in Translation : The Post-Colonial Context", he argues that the Indian threelanguage formula ignores minority languages, and proposes the recognition of existing dialects. He suggests that the absence of such a policy might be creating rifts between languages, since experience has shown that it is the non-recognition of languages, rather than their recognition, which leads to divisive movements. "Organic and Structural Pluralism : A Review of Translation Activity in India and Canada" by 
Lachmann M. Khubchandani reviews language dynamics of heterogeneous societies such as India and Canada. The author concludes that the role of translation in India is characterised by an unstructured complementary role, whereas in Canada it is guided by a highly structured adversary role between the two official languages.

A section on LANGUAGE POLICY AND PLANNING explores and compares these experiences in both contexts from a number of angles. Policies seem to be determined by social, cultural, as well as economic factors. Whereas in Canada linguistic policies have long been established, in India, the establishment of linguistic policies is much more complex. "Language Policy and Planning : An Indian Perspective" by D. P. Pattanayak examines the languages which were included in the Eighth Schedule of the Indian constitution, and comes to the conchusion that there was no coherent policy for the preference of one language over another. "Language Policy and Translation in Karnataka" by B. Mallikarjun shifts the focus from the national to the regional level. This author compares translations as statutory and voluntary activities and concludes that only the voluntary translations prove to be qualitatively acceptable. "Language Planning and Terminology : The Case of Quebec" by Monique C. Cormier and Paul St-Pierre discusses language planning and the implementation of linguistic policies in Quebec as a social issue dressed in linguistic terms. The French language acquires a symbolic dimension, whereby the rejection of the language is perceived as a rejection of its speakers. Here social issues leading to the implementation of linguistic policies in education and business include the role of the education of school-children in the survival of the French language, and the predominance of English speakers in positions of power in private business. In "Teaching the Other Official Language in Ontario Universities", Gabriel Moyal examines the political discourse on French language education in English Canada, and discovers that it is increasingly determined by fiscal and financial considerations rather than by arguments based on human values and needs.

A section entitled TRANSLATION PERSPECTIVES presents theoretical views of translation. New terms emerging to describe translation as an intercultural activity in post-colonial contexts tend to ascribe a positive value to translation. Translation scholars speak of renewal, transcreation and vitality instead of loss and assimilation. In 
"Translation in a Plurilingual Post-Colonial Context : India", Paul StPierre shifts the focus from the colonial relationship between English and Indian languages to the relationship between Indian languages, here Bengali and Oriya in Orissa. He finds that "translation in the post-colonial context underscores the connection of translation to power". In "Philosophy of Translation : Subordination or Subordinating : Translating Technical Texts from Sanskrit-Now and Then", Kapil Kapoor examines renewal of codes in cultural communities through translation. He claims that texts tend to freeze given cultural codes in a community, so that their meaning lose relevance in a given community. Translation undoes this process, by modernising the text. In "Culture as Translation", Barbara Godard analyses and compares the translation theories of Sherry Simon, Annie Brisset and Betty Bednarski, who shift the focus on cultural and linguistic heterogeneity in Quebec from one of damage to one of creation. "Translation : A Sociolinguistic Perspective" by R. S. Gupta argues that translation theorists have focused too intensely on preparing theories and notions of equivalence and have neglected to take sociolinguistic factors and the target culture into account. In "Translation and Cultural Politics in Canada" Sherry Simon observes that translation has remained marginal to cultural and literary studies in Canada. She attributes this to its early institutionalisation, and to the fact that in Canada the focus has been on intranational rather than international translation. She observes that translational paradigms reflecting a more complex interaction among various cultural communities in Canada are beginning to emerge. In pluralistic translation national identity is no longer predominant, but "becomes subordinate to a proliferation of micro-identities" (p. 202).

In TRANSLATION APPROACHES AND STRATEGIES, translation scholars describe and test the post-colonial strategies employed in cultural translation. "Translation as Assimilation /Appropriation in Canada and India" by $\mathrm{K}$. Chellappan argues that whereas translation in Canada is perceived as a form of cultural assimilation, Indian translators often use translation as a form of cultural subversion and appropriation. Consequently, the approaches used in translation are also different : Canadian translation is concerned with establishing and maintaining cultural difference, while translators in India are concerned with establishing unity. "Translation as Subversion : The Case of an Oriya Adaptation of Charles Dickens' A Tale of Two Cities" by Jatindra K. Nayak \& H.S. Mohapatra describes the regulated transformation of a text. 
A Dickens novel set during the French Revolution is adapted to describe an Oriya uprising of 1817. The use of real historical characters, such as a dispossessed Oriya militia with professedly feudal sympathies, turns the fictional tale into a historical account. "Language as Content : Literary Translation into English" by Sukrita Paul Kumar describes the feminist rewriting of Hasan Shak's novel Nashtar in 1790 as The Nautch Girl by Qurratulain Hyder, an eminent Urdu writer. Kumar notes that whereas colonial translations used to present Indian English as homogeneous, regional differences are now appearing in English translations, marking texts with a distinct Urdu, Punjabi or Tamil ring. The increasing appearance of regional differences in the translated text is also noted in "Re-Presentation of Indian Women in Translation" by N. Kamala, who surveys the paratext of several English anthologies of short stories by Indian women : Women Writing in India, Inner Spaces by Women from Kermala, Stories by Indian Women, Truth Tales, In Other Words. She discovers, however, that while editorial policies avoid the pitfalls of national stereotyping by highlighting regional differences, they often fail to take into account the diversity of women's experiences. Women's writings tend to be categorised as either feminist or non-feminist. In "Translating the "Indian" : Michael Ondaatje's The English Patient and Bharati Mukherjee's Darkness, Malashri Lal observes a different phenomenon in the Canadian context. Lal's analysis of representative strategies of immigrant writers in Canada reveals that although one would expect them to be sensitive to representational issues, both Ondaatje and Mukherjee resort to stereotyping in their portrayal of Indian characters. He wonders whether it is possible to achieve a cultural translation in literary works which reflects multicultural conditions. Whereas many essays in this volume focus on the colonial and post-colonial relations between English and Indian languages, this last essay serves as a reminder that English is not the only language which has been involved in the colonisation of India. "India, England, France : A Post-Colonial Translational Triangle" by Harish Trivedi treats the translation and reception of French literature in Hindi as part of a general trend of the translation from other European languages into Hindi at the beginning of the $20^{\text {th }}$ century. He analyses the translations of Anatole France by Premchad, a Hindi translator and one of the greatest Hindi novelists, to demonstrate that the appreciation and the appropriation of French literature by Hindi novelists served as a strategy to undermine the colonial power of the English language. 
Translation and Multilingualism leaves no doubt that where language is considered symbolic of culture, translation becomes a symbol of cultural interaction. The transnational dialogue between Indian and Canadian scholars has not only demonstrated that despite the similarity in their definition of language, the approaches to translational practices can be quite different, but also that the scholars from communities with similar linguistic configurations may share their experiences and insights to learn from each other. Whereas Quebec is hesitant about translation from the English, which it has historically perceived as a tool of cultural assimilation and oppression, Indian culture shares this concern, but also perceives translation as a means of enriching and strengthening regional languages. Here translators have reversed colonial translation strategies and used them to subvert colonial dominance. Shanta Ramakrishna observes that :

If in post-colonial Canada, particularly in Francophone Canada, translators seem to be keen on maintaining difference and preserving the cultural specificity of Québec, because of Quebec's sensitivity to language as a reflector of culture, in India there seems to be a keen desire to discover unity in diversity and create a pan-Indian literature through translations. Whereas Québec is seen to resist assimilation and appropriation, in India different languages seem to appropriate the common heritage through translation. (p. 20)

The comparison of linguistic and translational practices leads this reader to wonder why aboriginal languages and their translations in Canada or Quebec have not been included in this discussion. Considering that equality in linguistic and cultural representation is a central issue in Translation and Multilingualism, the absence of these linguistic communities is especially striking. Nonetheless, Translation and Multilingualism serves as a stimulating and informative springboard for further discussions and research into translational practices and policies.

Anke Rohde Université Concordia 